\title{
DIÁLOGOS ENTRE PRONERA E EDUCAÇÃO POPULAR: ALTERNATIVAS FRENTE À COLONIALIDADE DO SABER
}

Geraldo Miranda Pinto Neto ${ }^{1}$

\section{Resumo:}

O trabalho discute sobre a colonialidade do saber nas ciências sociais e reflete sobre alternativas frente à tal contexto. A produção do conhecimento e o saber universitário atuam para manter as elites no poder e contribuir com o processo civilizatório da colonização. Neste sentido, problematiza-se: É possível a construção de alternativas à colonialidade do saber no âmbito universitário? Apresenta-se o Programa Nacional da Reforma Agrária (Pronera) e o seu diálogo com a educação popular, enquanto mecanismo de construir outras formas de saber e fazer na produção de conhecimento social a partir da realidade dos oprimidos latinoamericanos.

Palavras-chave: Colonialidade do saber. Educação do Campo. Educação Popular. PósGraduação em Direitos Sociais do Campo. Pronera.

\section{DIALOGUES BETWEEN PRONERA AND POPULAR EDUCATION: ALTERNATIVES FRONT TO COLONIALITY OF KNOW}

\begin{abstract}
:
The paper discusses the coloniality of knowledge in the social sciences and reflects on alternatives to this context. The production of knowledge act to keep the elites in power and contribute to the process of colonization. In this way, it's problematic: Is it possible to construct alternatives to the coloniality of knowledge in the university context? The Pronera and your dialogue with popular education are presented as a mechanism to construct other forms of knowledge and action in the production of social knowledge based on the reality of the Latin American oppressed.
\end{abstract}

Keywords: Coloniality of knowledge. Field Education. Popular Education. Post-Graduation in Social Rights of the Rural. Pronera.

\section{Introdução}

O saber fazer universitário e a produção do conhecimento no âmbito das ciências sociais é o foco do presente artigo. O artigo decorre da atuação do autor na equipe executora da Especialização em Direitos Sociais do Campo (UFG/RG/INCRA/PRONERA/CNPq) entre 2013 e 2015 na prática da educação do campo e da educação popular através do Programa Nacional de Educação na Reforma Agrária (PRONERA). E do aprofundamento teórico através das temáticas da colonização e colonialidades, como do saber e do poder.

\footnotetext{
${ }^{1}$ Professor do Centro Universitário de Goiatuba - Unicerrado. Mestre em Direito, Estado e Constituição pela Universidade de Brasília (UnB). Graduado em Direito pela Universidade Federal de Goiás - Regional Goiás. Pesquisador vinculado ao Direito Achado na Rua (UnB) e ao Observatório Fundiário Goiano (OFUNGO/UFG). Correio eletrônico: neto.gmpn@gmail.com.
} 
Ao aliar as duas experiências, através da pesquisa empírica em direito, o trabalho busca responder as seguintes problematizações: É possível a construção de alternativas à colonialidade do saber no âmbito universitário? Se sim, o Pronera pode ser considerado uma destas alternativas que buscam novos saberes e fazeres universitários?

Para responder tais anseios utiliza-se a seguinte metodologia: a pesquisa empírica, com enfoque na vivência do autor no âmbito da experiência do Pronera na UFG e o estudo de documentos relacionados à educação do campo e a Especialização em Direitos Sociais do Campo. Conjuntamente com a revisão bibliográfica de obras de Paulo Freire (1996), Enrique Dussel (2007), Aníbal Quijano (2000) e Lander (2000).

Para tanto, o primeiro capítulo é composto pela apresentação do Pronera, a sua criação, seus objetivos, princípios, a metodologia da pedagogia da alternância, o público alvo e o caráter transformador da educação através da formulação de sujeitos coletivos de direito em prol do fortalecimento da identidade camponesa. Posteriormente é relatada a experiência da Especialização em Direitos Sociais do Campo (UFG/PRONERA/CNPq).

O segundo capítulo é feito do diálogo entre a experiência do Pronera com a teoria do conhecimento da educação popular. Ou seja, encontram-se proximidades entre a educação do campo e a educação popular, por se tratar de experiências voltadas para a superação das opressões vivenciadas pelos sujeitos da América-Latina.

No terceiro capítulo há reflexões sobre a colonização do continente americano através da usurpação das terras e das gentes, e o papel do saber eurocêntrico na legitimação da conquista. Conjuntamente, há reflexões sobre a continuidade do caráter colonial na produção do conhecimento, caracterizando a colonialidade do saber. Posteriormente, apresenta-se as principais formulações de saberes e fazeres universitários alternativos ao do padrão colonial.

Dessa maneira, o objetivo do presente trabalho é construir reflexões a partir do conflito dialético entre a experiência do Programa Nacional de Educação na Reforma Agrária com a construção de um saber eurocêntrico.

\section{O Programa Nacional de Educação na Reforma Agrária (PRONERA) e a Especialização em Direitos Sociais do Campo (UFG-CNPq-INCRA)}

A pretensão do presente tópico apresenta de maneira geral o Programa Nacional de Educação na Reforma Agrária (PRONERA) e relata a experiência da Especialização em Direitos Sociais do Campo - Residência Agrária realizada na Universidade Federal de Goiás 
- Regional Goiás (UFG) em parceria com o CNPq e com o INCRA entre os anos de 2013 e 2015. A partir da apresentação da experiência será possível refletir sobre a construção de elementos que rompem e contestam a colonialidade do saber.

\subsection{O Programa Nacional de Educação na Reforma Agrária (PRONERA): a} consolidação institucional da criação do direito à educação do campo

O Estado Moderno foi construído a partir da negação de direitos para diversos segmentos e grupos populares. Dentre estes, encontram-se as populações do campo. Através de fatores legais, políticos, econômicos e sociais de predomínio neoliberal, houve a prevalência do latifúndio e posteriormente do agronegócio, que conjuntamente com a supremacia do urbano pelo rural, os trabalhadores rurais foram incluídos na exclusão social (SOUSA, 2012).

Um dos direitos negados para os povos do campo foi o direito à educação. Afinal, os(as) trabalhadores(as) rurais não são incluídos em políticas universalistas do direito à educação. E quando possuem o acesso à educação formal, não há o respeito ao contexto e à diversidade de tais sujeitos, o que não contribui com a formação integral do sujeito do campo.

Como retrato da exclusão no direito à educação, encontram-se os dados fornecidos pelo extinto Ministério do Desenvolvimento Agrário (MDA): através de uma análise quantitativa observa-se que na região Centro-Oeste o índice médio de pessoas do campo não alfabetizadas é de 13,86\% e apenas $1 \%$ completou algum curso de nível superior (MDA, 2011:10).

Percebe-se "que durante grande parte da história brasileira não se discutiu a educação para trabalhadores rurais. E, quando o debate foi colocado, este se fez sob o paradigma do Ruralismo Pedagógico" (SOUSA, 2012:112). Desta maneira:

Quando se considera a educação para os povos do campo, encontra-se, de um lado, uma história de exclusão, de não efetivação do direito a educação para este segmento da sociedade, cujas consequências ainda estão presentes. E, de outro lado, a construção de políticas populares alternativas (SOUSA, 2012:113).

Diante do contexto de exclusão da população do campo (seja através da dificuldade no acesso, seja pela ausência de pertencimento) à educação formal, foram construídas diversas experiências de educação realizadas fora do âmbito estatal, através da mobilização de movimentos sociais e associações (SOUSA, 2012:116).

Através “da exclusão e da capacidade de aglutinação, os camponeses ao longo da história procuram se organizar em movimentos sociais para resistir e reivindicar espaço na 
sociedade excludente" (SOUSA; FREITAS 2008:1). Neste sentido, os sujeitos do campo rompem com opressões e espoliações, assumindo o protagonismo da reinvenção e transformação dos seus destinos em sua direção histórica à emancipação (SOUSA JÚNIOR, 2008:5), através da construção de experiências de educação do campo.

No final da década de noventa, as experiências não-estatais de realização da educação do campo começaram a se reunir através dos Encontros Nacionais dos Educadores da Reforma Agrária (ENERA). E diante articulações, manifestações e lutas, por dentro e por fora do Estado, foi criado o Programa Nacional de Educação na Reforma Agrária $(\text { PRONERA })^{2}$.

Ou seja, sujeitos coletivos de direito ocuparam a educação pública brasileira para o desenvolvimento e consolidação da educação do campo nas vias institucionais. Como se observa:

O Pronera nasceu em 1998, a partir das lutas dos movimentos sociais e sindicais do campo. Desde seu nascedouro, o programa vem garantindo acesso à escolarização a milhares de jovens e adultos, trabalhadores de áreas de reforma agrária que, até então, não haviam tido o direito de se alfabetizar, tampouco o direito de continuar os estudos em diferentes níveis de ensino (IPEA, 2015:9).

Um dos principais objetivos do Pronera é:

Oferecer educação formal aos jovens e adultos beneficiários do II Plano Nacional de Reforma Agrária (PNRA), nos níveis de ensino básico, superior e pós-graduação, Residência Agrária, e áreas do conhecimento ofertados em regime de alternância e nas modalidades de jovens e adultos e Educação do Campo (MDA, 2014:12).

Percebe-se que o programa se consolidou enquanto instrumento de luta e reivindicação por melhores condições de vida no campo, desta maneira, a educação contribui de maneira efetiva para atingir tais melhorias. O Pronera pretende a ampliação do acesso ao direito à educação, conjuntamente com a ampliação do direito à terra, ao território, à produção e à vida (IPEA, 2015:9).

O Pronera compreende a educação enquanto um instrumento público responsável por implementar e garantir novos padrões nas relações de trabalho, na organização do território e na relação com a natureza nas áreas da reforma agrária (MDA, 2014:7). Reforça-se tal compromisso através de uma análise sobre os princípios do programa, quais sejam: a

\footnotetext{
${ }^{1}$ Conceituação do Programa: “O Programa Nacional de Educação na Reforma Agrária (PRONERA) é uma política pública de Educação do Campo, desenvolvida nas áreas de reforma agrária e executada pelo Ministério do Desenvolvimento Agrário (MDA), por meio do Instituto Nacional de Colonização e Reforma Agrária - Incra. Seu objetivo é fortalecer o meio rural enquanto território de vida em todas as suas dimensões: econômicas, sociais, políticas, culturais e ética" (MDA, 2014:7).
} 
democratização do acesso à educação; a participação (as demandas educacionais são feitas pelas comunidades das áreas de reforma agrária e suas organizações); a interação; a multiplicação; a parceria (parceria na gestão participativa e construção coletiva no acompanhamento do projeto); o princípio do diálogo; da práxis; da transdisciplinaridade e o princípio da equidade (MDA, 2014:10).

Os cursos do Pronera são realizados através do regime de alternância. "Esse regime compreende a alternância regular de períodos de estudos (tempo escola e tempo comunidade), que considera o contexto socioambiental e a diversidade cultural do campo, em todos os estados do território" (IPEA, 2015:10). Os beneficiários do Programa são:

Seus beneficiários são jovens e adultos que, a partir da sua inserção no programa, reconhecem-se como sujeitos de direitos; como sujeitos capazes de construir suas identidades de povo camponês e produzir, no cotidiano dos assentamentos e acampamentos da reforma agrária, alternativas de transformação e enfrentamento ao modelo agrícola dominante, que expulsa crescentemente os povos do campo do seu território. O Pronera é um instrumento de resistência que, através da educação, da escolarização e da formação, constitui sujeitos coletivos conscientes de seu papel histórico e social (IPEA, 2015:9).

O Pronera promove educação formal ao desenvolver: projetos de Educação de Jovens e Adultos (EJA), cursos técnicos profissionalizantes de nível médio, cursos de nível superior e de especialização, abarcando várias áreas de conhecimento, como pedagogia, saúde, medicina veterinária, serviço social e direito (IPEA, 2015:9). Neste sentido, "vem cumprindo seu objetivo maior, que é fortalecer a educação nas áreas de reforma agrária, estimulando, propondo, criando, desenvolvendo e coordenando projetos educacionais" (IPEA, 2015:10).

O Pronera traz a necessidade do diálogo entre a academia com os movimentos sociais do campo, na construção de novos paradigmas educacionais que preconizam uma sincronicidade com a luta política-ideológica que tais movimentos protagonizam (SÁ, 2009:373.). Coma inserção das lutas dos movimentos sociais dentro da universidade, pressupõe-se a necessidade de reflexão e construção de novos saberes e fazeres pedagógicos.

E é dentro dessa perspectiva transformadora que o PRONERA chega à Universidade Federal de Goiás, no município de Goiás-GO, inicialmente com a consolidação da primeira turma em Direito para beneficiários da reforma agrária e agricultura familiar, a Turma Evandro Lins e Silva (2007-2012); e posteriormente, com a Residência Agrária em Direitos Sociais do Campo (2013-2015). Agora, com a turma 'Fidel Castro', iniciada em 2015. 


\subsection{A experiência da Especialização em Direitos Sociais do Campo - Residência} Agrária (UFG-INCRA-CNPq-PRONERA)

Entre os anos de 2013 e 2015 ocorreu a Especialização em Direitos Sociais do Campo - Residência Agrária na Universidade Federal de Goiás - Regional Goiás, o curso foi criado e consolidado a partir do Pronera. Para a apresentação da experiência, para além da vivência do autor na execução do projeto, serão analisados os seguintes documentos: o Projeto Político Pedagógico do Curso da especialização; o Perfil da Turma; e o resumo expandido intitulado 'Pós-Graduação em Direitos Sociais do Campo: Caminhos para a construção da Universidade Popular'3.

A UFG-Regional Goiás tem demonstrado acúmulo nas propostas do PRONERA relacionadas com o campo do Direito. Em agosto de 2012 houve a formatura de 60 bacharéis em direito, camponeses(as) e agricultores(as) familiares com a conclusão da Turma Evandro Lins e Silva. Enquanto campo imediato para a capacitação e especialização destes bacharéis foi construída a Especialização em Direitos Sociais do Campo, abarcando outros(as) beneficiários do Pronera (que não se graduaram com a Turma Evandro Lins e Silva) e pessoas que realizam assessoria técnica em áreas de reforma agrária. A especialização surge e se consolida para valorizar o seguinte objetivo:

Fortalecer a educação do campo e a cultura jurídica, crítica e plural, como estratégia do desenvolvimento humano vinculada aos projetos de construção do bem viver, no âmbito econômico, social e cultural do campo, a partir da busca pelas novas práticas produtivas, pedagógicas e laborais (UFG, 2012:2).

A especialização contou com 55 educandos e educandas, de diversas regiões, organizações e áreas do conhecimento. Na turma existiam egressos de 12 cursos de graduação diferentes, indo desde a área da antropologia até a área de zootecnia. No entanto, a maioria da turma era formada em Direito (30 educandos, entre eles(as), 23 egressas(os) da Turma Evandro Lins e Silva) e contêm ampla participação de pedagogas(os) que atuam na educação escolar rural.

Os estudantes são de diversas regiões do país, abarcando 14 estados e o Distrito Federal. Vale ressaltar, que a maioria dos educandos e educandas são do estado de Goiás (29). Há uma pluralidade de organizações e movimentos sociais, dentre eles: MST, MCP, MPA,

\footnotetext{
${ }^{3}$ Resumo produzido pela equipe executora do projeto em outubro de 2013. Equipe executora: Allan Hahnemann, Cássia Rosa, Emília Joana de Oliveira, Erika Macedo Moreira (coordenadora do projeto), Geraldo Neto, Marcos Antônio Cunha, Pedro Guilherme Faria, Ranielle Caroline de Sousa, Renato Calixo, Rosana Cebalho Fernandes e Sinara Sá. Foi publicado nos anais do $10^{\circ}$ Congresso de Pesquisa, Ensino, e Extensão da Universidade Federal de Goiás.
} 
CONTAG, FETAEG, RENAP, CETA, Movimento Geraizeiro, dentre diversos outros ${ }^{4}$. Percebe-se que a pluralidade de organizações, de localidades e de áreas do conhecimento são fundamentais para garantir um aprofundamento sobre a realidade agrária em nível nacional a partir dos oprimidos sociais envoltos na luta do campo.

O curso foi formulado a partir da metodologia da pedagogia da alternância. Tal metodologia alterna o tempo de estudo (desenvolvido no âmbito da universidade) e o tempo de estudo e prático desenvolvido na comunidade (o tempo comunidade). A proposta metodológica se fundamenta a partir dos instrumentos de construção do conhecimento a partir dos aspectos da realidade do campo brasileiro, valorizando a prática inter ou transdisciplinar (MDA, 2014:21).

A partir de tal metodologia, a experiência contou com três tempos escola (realizado em julho de 2013 e janeiro e julho de 2014) e os tempos comunidades (realizado no intervalo destes períodos). Para a sistematização da experiência houve o Congresso de Encerramento 'Ocupar, Resistir e Produzir Saberes' realizado em abril de 2015.

A Especialização em Direitos Sociais do Campo, propiciou a articulação entre educandos(as), professoras(es), graduandos(as) em Direito pela UFG, lideranças de movimentos sociais e demais pesquisadores em Núcleos de Extensão e Pesquisa (NEPs). Houve a consolidação de quatro NEPs: em Assessoria Jurídica Popular, Educação do Campo, Agroecologia e Territórios e Documentação e Memória (NEP transversal responsável por garantir a memória das ações desenvolvidas). A partir desta proposta, houve o diálogo entre os trabalhos executados e a realização de atividades estruturantes ${ }^{5}$.

Outra inovação diz respeito à valorização da prática da pesquisa-ação e da ecologia dos saberes, ou seja, houve o incentivo para que as(os) educandas(os) realizassem intervenções diretas em suas comunidades voltadas para a promoção e defesa dos direitos sociais no campo. Santos (2015:55) apresenta:

A pesquisa-acção e a ecologia dos saberes são áreas de legitimação da universidade que transcendem a extensão uma vez que tanto actuam ao nível desta como ao nível

\footnotetext{
${ }^{4}$ Dados obtidos a partir do Perfil da Turma realizado em 23 de janeiro de 2013. Acervo da Pós-Graduação em Direitos Sociais do Campo.

${ }^{5}$ Dentre as ações estruturantes realizadas pode-se destacar: a) o NEP de Assessoria Jurídica Popular realizou o Seminário Advocacia, Trabalho e Movimentos Sociais em abril de 2015, através da articulação com a Rede Nacional de Advogados e Advogadas Populares (RENAP) e realização de diversas oficinas envolvendo Direito à Terra e ao Território; b) O NEP de Educação do Campo realizou a publicação de um livro infantil e realizou Diagnósticos Rurais Participativos (DRPs) em quatro escolas do município de Goiás (que resultaram na produção de documentários); c) o NEP de Agroecologia e Território se articulou para apresentar trabalhos em seminários internacionais sobre a produção agroecológica.
} 


\begin{abstract}
da pesquisa e da formação. A pesquisa-acção consiste na definição e execução participativa de projetos de pesquisa envolvendo comunidades e organizações sociais populares a braços com os problemas cuja solução pode beneficiar dos resultados da pesquisa. Os interesses sociais são articulados com os interesses científicos dos pesquisadores e a produção do conhecimento científico ocorre estreitamente ligada à satisfação de necessidades dos grupos sociais que não têm poder para pôr conhecimento técnico e especializado ao seu serviço pela via mercantil.
\end{abstract}

Com a execução do projeto, percebe-se que houveram diversos acúmulos e reflexões importantes no âmbito da questão agrária aliadas com o conhecimento jurídico. Dentre as questões: a) a pluralidade de campos do saber que contribuíram para a prática inter e transdisciplinar; b) a valorização do contexto das(os) educandas(os) para a formulação das disciplinas, execução dos trabalhos de campo, tempos comunidade e realização da pesquisaação; c) a inovação de práticas político-pedagógicas no campo jurídico através da educação do campo; d) inovações na forma de produzir conhecimento científico, rompendo com a individualidade e com a teoria distante de prática, através da valorização da pesquisa-ação, da ecologia dos saberes, da articulação entre a teoria e prática e do saber compartilhado e coletivizado através dos NEPs; e) produção de conhecimento aliado com as demandas populares de coletivos e movimentos sociais que lutam pela terra e território enfrentando o agronegócio e o latifúndio no Brasil; f) o ingresso de movimentos sociais na universidade, no campo científico e jurídico, enquanto possibilidade de oxigenar práticas e teorias.

\title{
3. Diálogos entre o PRONERA e Paulo Freire
}

A partir da experiência relatada sobre a 'Especialização em Direitos Sociais no Campo' (UFG), enquanto escopo para reflexão sobre o Pronera, se intui que muitos dos objetivos, pressupostos, princípios, metodologias e resultados dialogam com a teoria do conhecimento da educação popular, que possui enquanto referencial teórico e prático, Paulo Freire (1921-97).

Neste sentido, para compreender os principais pressupostos teóricos da teoria do conhecimento da educação popular remete-se à leitura sobre a biografia de Paulo Freire escrita por Ângela Antunes (2014) e a obra Pedagogia da Autonomia (FREIRE, 1996). Adiante serão expostas as questões que realizam o diálogo da educação popular com o Pronera. 
A educação nos projetos do Pronera é encarada enquanto uma reflexão sobre o próprio ser humano e a sua capacidade de interpretar o mundo e agir para transformá-lo (ANTUNES, 2014:377), ou seja, a prática de ensinar e apreender se desenvolvem numa dimensão social de formação humana (FREIRE, 1996:12). Há o questionamento da educação bancária (preocupada com a simples transmissão do conhecimento) e busca instaurar uma educação emancipatória. Percebe-se tal fator através da realização de metodologias participativas (debates e rodas de conversa) e uma ampla participação na busca pela cidadania e pela democracia.

A educação popular se pauta na necessidade de reflexão sobre a própria prática, através do movimento ação-reflexão-ação (ANTUNES, 2014:377); Como se observa:

Por que não discutir com os alunos a realidade concreta a que se deva associar a disciplina cujo conteúdo se ensina, a realidade agressiva em que a violência é a constante e a convivência das pessoas é muito maior com a morte do que com a vida? Por que não estabelecer uma necessária "intimidade" entre os saberes curriculares fundamentais aos alunos e a experiência social que eles têm como indivíduos? Por que não discutir as implicações políticas e ideológicas de um tal descaso dos dominantes pelas áreas pobres da cidade? A ética de classe embutida neste descaso? (1996:33-34).

O Pronera apresenta uma grande preocupação com a interação da ação e da reflexão, como se observa pela consagração de princípios como a práxis, da produção do conhecimento aliando a prática e a teoria (MDA, 2014:10); A metodologia utilizada nos projetos da educação do campo também favorecem este encontro (teoria e prática) através da pedagogia da alternância (MDA, 2014:21).

Outra reflexão e opção trazida por Paulo Freire diz respeito ao combate à educação descontextualizada. Percebe-se que o reconhecimento do 'chão', o contexto e a realidade em que os educandos estão inseridos deve ser encarado enquanto ponto de partida para a aprendizagem (ANTUNES, 2014:378). E além, de respeitar os saberes dos educandos, devese respeitar os saberes construídos na prática comunitária, e os professores e professoras devem discutir com os alunos e alunas a razão da existência destes saberes em relação ao ensino dos conteúdos (FREIRE, 1996:33).

Os próprios processos de criação da educação do campo surgem a partir da negação da educação hegemônica, ao perceberem que essa, não valoriza o contexto dos educandos e educandas que vivem no mundo rural (SOUSA, 2012). Ou seja, a educação do campo apresenta enquanto parâmetro e horizonte a valorização do contexto da(o) educanda(o). 
A Especialização em Direitos Sociais do Campo (UFG/PRONERA/CNPq) apresenta questões inovadoras na valorização do contexto. Dentre elas: a) a existência de disciplinas com ementas abertas que seriam construídas a partir das demandas e necessidades de formação do próprio estudante; b) a construção destas disciplinas conforme o perfil dos alunos e alunos, com frequente valorização para as disciplinas de Assessoria Jurídica Popular (frente aos diversos(as) advogados(as) populares na turma) e de educação do campo (pois a turma conta com diversas(os) professoras(es) que atuam nas escolas rurais); c) a criação de um Núcleo de Extensão em Pesquisa a partir da reivindicação das(os) educandas(os) (o de Agroecologia e Territórios); d) a articulação de diversos momentos de reflexão conjunta sobre as realidades e atuações diversas.

As experiências do Pronera propiciam um aprendizado e produção de conhecimentos, que são aliados às causas e demandas populares. Ou seja, é a partir da realidade de camponesas(es) e agricultores(as) familiares em que se dá o processo de aprender e ensinar. Neste sentido, há uma "necessidade de transformação, da reinvenção do mundo em favor das classes oprimidas" (ANTUNES, 2014:378). Ou seja, uma pedagogia comprometida com a melhoria das condições de vida das populações socialmente oprimidas (ANTUNES, 2014:380). O que representa o ponto de vista dos 'condenados da Terra' e dos excluídos, como remete Paulo Freire (1996:16). Neste sentido, rompe com a pretensa neutralidade do saber acadêmico, e apresenta um compromisso social na produção deste conhecimento.

Aliado ao compromisso com os oprimidos sociais, o processo de conhecimento entre educadores e educandos deve-se assumir um papel crítico de sujeitos cognoscentes, através da reflexão sobre o seu estar sendo no mundo, enquanto capaz do poder de transformar a sua realidade; ou seja, a educação enquanto um ato político (ANTUNES, 2014:380). A educação tem papel fundamental para transparecer aos educandos a "maneira de estar no mundo e com o mundo, como seres históricos, é a capacidade de, intervindo no mundo, conhecer o mundo." (FREIRE, 1996:31). A experiência da Especialização em Direitos Sociais do Campo apresenta este intuito a partir do respaldo para desenvolver a pesquisa-ação e a ecologia dos saberes.

Os pressupostos da educação popular exigem o respeito ao saber popular, o que implica necessariamente no respeito ao contexto cultural. Exige-se o diálogo enquanto condição essencial para o conhecimento (ANTUNES, 2014:381). Percebe-se que a "educação, 
numa perspectiva libertadora, exige a dialogicidade, portanto, a leitura do mundo coletiva" (ANTUNES, 2014:383). Afinal:

[...] teríamos entendido com facilidade a importância das experiências informais nas ruas, nas praças, no trabalho, nas salas de aula das escolas, nos pátios dos recreios, em variados gestos dos alunos, de pessoal administrativo, de pessoal docente se cruzam cheios de significação (FREIRE, 1996:49).

Percebe-se a valorização do saber popular nas experiências do Pronera, afinal, as organizações sociais, com todos os seus saberes, simbologias e misticismo ocupam as salas de aulas com as bandeiras, modos e organicidade. Há que se destacar também, que a própria criação da educação do campo surge a partir de saberes e experiências populares que não tinham ligação estatal. O Pronera foi uma consequência destes mecanismos de educação informal articulados com a disputa de projeto político de Estado. Neste sentido, percebe-se que a política pública específica para a educação do campo amplia e diversifica as fontes legítimas de saberes e propicia a coerência entre o 'saber-fazer' e o 'saber-ser-pedagógico' (FREIRE, 1996:12).

As formulações teóricas e práticas da educação popular incentivam a 'vocação de ser mais' dos educandos, que através da práxis, ocorre o processo de humanização contínua (ANTUNES, 2014:377). Conjuntamente com a 'vocação de ser mais' há a fé e a esperança nos seres humanos (ANTUNES, 2014:382).

$\mathrm{O}$ ato de aprender e ensinar exige um projeto político-pedagógico voltado à formação da cidadania ativa, à transformação social e da construção à cultura da solidariedade (ANTUNES, 2014:383). Paulo Freire apresenta que tais fatores são essenciais para a construção da sociedade:

A solidariedade social e política de que precisamos para construir a sociedade menos feia e menos arestosa, em que podemos ser mais nós mesmos, tem na formação democrática uma prática de real importância. A aprendizagem da assunção do sujeito é incompatível com o treinamento pragmático ou com o elitismo autoritário

E continua: dos que se pensam donos da verdade e do saber articulado. (FREIRE, 1996:47)

É nesse sentido que reinsisto em que formar é muito mais do que puramente treinar o educando no desempenho de destrezas. E por que não dizer também da quase obstinação com que falo de meu interesse por tudo o que diz respeito aos homens e às mulheres, assunto de que saio e a que volto com o gosto de quem a ele se dá pela primeira vez. Daí a crítica permanentemente presente em mim à malvadeza neoliberal, ao cinismo de sua ideologia fatalista e a sua recusa inflexível ao sonho e à utopia (FREIRE, 1996:15). 
Percebe-se que o Pronera é reflexo da construção de cidadania ativa, de transformação social e de construção da cultura da solidariedade. E tais diretrizes de participação nas decisões do Estado através de enfrentamentos e o anseio por mudanças são presentes em seus diversos projetos. Afinal, os movimentos sociais ocupam instituições de ensino e geram novos fazeres e reflexões.

A experiência da Especialização em Direitos Sociais do Campo traz diversas inovações para se pensar a universidade a partir da prática dos movimentos sociais. Afinal, conta com integrantes dos movimentos sociais dentro da Coordenação Pedagógica; há uma valorização aos conhecimentos e saberes oriundos dos(as) educandos(as) e dos seus respectivos contextos; os movimentos sociais deram uma oxigenação do saber universitário, trazendo diversas temáticas sócio-jurídicas que são 'esquecidas' dos bancos universitários; e são as lutas populares camponesas as responsáveis por garantir as novas formas de produção do conhecimento.

Desta maneira, percebe-se um intrínseco diálogo entre o Pronera e a educação do popular, através dos seus principais elementos de construção pedagógica, política e social.

\section{Colonialidade do saber: é possível a construção de alternativas decoloniais?}

O processo de colonização europeia na América Latina foi responsável por impor novas relações de mundo e formas de percepção da realidade. Uma interferência violenta, principalmente, sobre as relações humanas, a natureza e as formas de conhecer o mundo. A conquista ibérica foi o momento fundante dos seguintes processos históricos: a modernidade e a organização colonial do mundo (LANDER, 2000:6).

Carlos Marés ${ }^{6}$ apresenta que a colonização espanhola/portuguesa sob a América Latina se consolidou através de duas formas: a destruição da natureza e a destruição das gentes. $\mathrm{O}$ autor apresenta que a América foi responsável por alimentar o continente europeu, no entanto, a flora que não fosse enquadrada enquanto alimento poderia ser destruída caracterizando a destruição da natureza.

Já a destruição das gentes se deu pela morte dos povos indígenas que rejeitaram a condição de escravos e sob a morte e a escravidão dos africanos em território nacional

\footnotetext{
${ }^{6}$ Texto decorrente da exposição de Dr. Carlos Frederico Marés de Souza Filho durante a Aula Inaugural da PósGraduação em Direitos Sociais do Campo - Residência Agrária, ministrada em 12 de julho de 2013. Disponível em: http://www.direitosocioambiental.com.br/aula-usurpacao-das-terras-e-das-gentes/ Acesso30 de outubro de 2014.
} 
(MARÉS, 2013). Tais formas se consolidaram pela concepção da existência de raças superiores (a europeia) e de raças inferiores (indígenas e africanas) (QUIJANO, 2000). Neste sentido:

Uma vez reconhecidos os territórios, geograficamente, se passava ao controle dos corpos, das pessoas: era necessário 'pacificá-las' - se dizia na época. O que estabelece sobre outros povos a dominação do mundo espanhol (posteriormente do europeu em geral) é um militar, um guerreiro. O 'Conquistador' é o primeiro homem moderno ativo, prático, que impõem a sua 'individualidade' violenta a outras pessoas, ao Outro $^{7}$ (DUSSEL, 1994:40 - tradução livre).

Tal usurpação das terras e das gentes se consolidou através do processo que DUSSEL (1994:8) denomina de encobrimento do outro. Como apresenta:

\begin{abstract}
A modernidade se originou nas cidades europeias medievais, livres, centros de enorme criatividade. Mas nasceu quanto a Europa pode confrontar-se com o Outro e controla-lo, vence-lo, violentar; quando pode definir como um ego descobridor, conquistador, colonizador da alteridade constitutiva da mesma Modernidade. De todas maneiras, esse outro não foi descoberto como outro, foi encoberto como o mesmo que a Europa já era desde sempre ${ }^{8}$ (DUSSEL, 1994:8 - tradução livre).
\end{abstract}

Há que se destacar que o processo de colonização se estendeu sobre duas maneiras: um processo militar e prático e outro processo de controle sobre os corpos; ambas as formas exercidas de maneira violenta diante o choque entre o mundo europeu e o mundo indígena (DUSSEL, 1994).

O processo militar e prático, ocorreu no período denominado da 'conquista' europeia sobre o solo latino-americano, em que os identificados enquanto 'outros' (povos latinos e africanos) deveriam ser incorporados na totalidade dominadora do mundo europeu (DUSSEL, 1994:41) - que veio para conquistar, dominar e matar. Houve então, uma relação militar de conquistador - conquistado, em que o primeiro tinha uma tecnológica militar desenvolvida contra a tecnologia militar subdesenvolvida. Neste sentido, a primeira experiência da modernidade foi a superioridade do ser europeu sobre o 'outro' considerado enquanto primitivo, rústico e inferior (DUSSEL, 1994:44).

\footnotetext{
7 "Una vez reconocidos los territorios, geográficamente, se pasaba al control de los cuerpos, de las personas: era necesario "pacificarlas" - se decía en la época-. El que establece sobre otros pueblos la dominación del mundo español (posteriormente del europeo en general) es un militar, un guerrero. El "Conquistador" es el primer hombre moderno activo, práctico, que impone su "individualidad" violenta a otras personas, al Otro" (DUSSEL, 1994:40).

8 "La Modernidad se originó en las ciudades europeas medievales, libres, centros de enorme creatividad. Pero "nació" cuando Europa pudo confrontarse con "el Otro" y controlarlo, vencerlo, violentarlo; cuando pudo definirse como un "ego" descubridor, conquistador, colonizador de la Alteridad constitutiva de la misma Modernidad. De todas maneras, ese Otro no fue "des-cubierto" como Otro, sino que fue "en-cubierto" como "lo Mismo" que Europa ya era desde siempre" (DUSSEL, 1994:8).
} 
Posterior ao processo militar, houve a colonização da vida cotidiana dos indígenas e escravos africanos. O resultado da práxis da guerra e da violência pura foi o domínio erótico, pedagógico, cultural, econômico (DUSSEL, 1994:49) - ou seja, aquilo que Foucault denominaria de controle dos corpos. Houve o domínio dos corpos através do machismo, da cultura, das novas relações de trabalho e das instituições burocráticas que foram criadas. $\mathrm{Ou}$ seja, houve a consagração da dominação do outro. Tal fenômeno foi responsável por começar a domesticação, colonização e dominação dos outros (os 'diferentes' dos europeus) (DUSSEL, 1994:56).

Dentre as formas de domínio dos corpos encontra-se o caráter colonial da constituição dos saberes:

Com o inicio do colonialismo na América começa não só a organização colonial do mundo, mas, simultaneamente, começa a constituição colonial dos saberes, das linguagens, da memória e do imaginário. Se dá início ao longo processo que culminará nos séculos XVIII e XIV no qual, pela primeira vez, se organiza a totalidade do espaço e do tempo - todas as culturas, povos e territórios do planeta, presentes e passados - numa grande narrativa universal. Nessa narrativa, a Europa é o centro geográfico e a culminação do movimento temporal. Neste período moderno novo/colonial se dão os primeiros passos na articulação das diferenças culturais de hierarquias cronológicas $^{9}$ (LANDER, 2000:6 - grifo nosso - tradução livre).

Diante a caráter colonial do saber houve a consagração do saber eurocêntrico, enquanto concepção teórica de que só existe uma forma de pensar e agir no mundo corretamente, o modo 'europeu', as demais culturas foram subsumidas (QUIJANO; LANDER, 2000). Afinal: "Na modernidade eurocêntrica, da invasão e da posterior conquista da América em 1492, o pensamento político definiu em geral o poder como dominação" (DUSSEL, 2007:25).

Tal dominação-supressão cultural teve a contribuição do modo de produção capitalista (principalmente sob a sua perspectiva liberal) como se observa:

A política liberal supôs tácita e eurocentricamente a cultura ocidental como a civilização sem mais, universal, a qual, em seu desenvolvimento moderno, se importaria a todas as outras culturas, selvagens, subdesenvolvidas ou atrasadas. A Modernidade, que começou com a conquista do Caribe e do México em primeiro lugar, impôs sua cultura como superior, e produziu genocídios culturais espantosos sobre as grandes culturas milenares (asteca, maia, inca, bantu, chinesa, indostânica,

\footnotetext{
9 "Con el inicio del colonialismo en América comienza no sólo la organización colonial del mundo sino simultáneamente - la constitución colonial de los saberes, de los lenguajes, de la memoria y del imaginario. Se da inicio al largo proceso que culminará en los siglos XVIII y XIX en el cual, por primera vez, se organiza la totalidad del espacio y del tiempo - todas las culturas, pueblos y territorios del planeta, presentes y pasados - en una gran narrativa universal. En esta narrativa, Europa es - o ha sido siempre - simultáneamente el centro geográfico y la culminación del movimiento temporal. En este período moderno temprano/colonial, se dan los primeros pasos en la 'articulación de las diferencias culturales en jerarquías cronológicas'” (LANDER, 2000:6 grifo nosso).
} 
islâmica, etc.). O capitalismo também supõe a cultura ocidental como a única universal" (DUSSEL, 2007: 144).

Através do contexto eurocêntrico e colonial, aliado com os pressupostos da modernidade, do liberalismo e do capitalismo foi construída a noção de universalidade a partir da experiência europeia. A leitura histórica do tempo e do espaço sobre a experiência humana foi organizada a partir dos pressupostos particulares de tal continente. Ou seja, houve a construção de um universalismo que não é universal, ao contrário, que é excludente, nega os direitos, culturas e saberes diferentes dos pressupostos liberais (LANDER, 2000:6).

A construção histórica a partir da narrativa 'universal' europeia gera uma série de implicações para as ciências sociais. Como a naturalização da sociedade liberal, enquanto única possibilidade para a sociedade e para a construção do saber; e da "superioridade evidente deste modelo de organização social - de seus países, cultura, história e raça - que é demonstrada tanto pela conquista e submissão dos demais povos do mundo, como pela 'superação' histórica das formas anteriores de organização social” (LANDER, 2000:9 tradução nossa).

Através da construção eurocêntrica, de perspectiva universalista, a modernidade se constitui enquanto dispositivo de um conhecimento colonial e imperial. Formas de ser, de organização social e de formas de saber, diversas do padrão europeu/liberal/colonial são transformadas em diferentes, primitivas, inferiores e não conseguem ser modernas (LANDER, 2000:10).

Percebe-se que os efeitos coloniais possuem continuidade nas sociedades atuais, caracterizando a colonialidade do $\operatorname{poder}^{10}$ (QUIJANO, 2000) e a colonialidade do saber (LANDER, 2000). Tais categorias representam percepções sobre fatores sociais que continuaram o efeito colonial, em sociedades em momentos pós-colonização. Entende-se enquanto colonialidade do saber:

Neste sentido é possível afirmar que, em todo o mundo pós-colonial, as ciências sociais tem servido mais para o estabelecimento do contraste com a experiência histórico cultural universal (normal) da experiência europeia, (ferramentas de

10 Aníbal Quijano (2000:122; 2002:4) apresenta que a colonialidade do poder tem a sua origem e caráter colonial, no entanto, se desenvolve de maneira mais estável e duradoura do que o colonialismo. São fatores coloniais que impregnam todas as áreas de existência social e representam a profunda e eficaz dominação social, material e intersubjetiva, constituindo-se enquanto base universal de dominação política. Como exemplo da colonialidade do poder, o autor apresenta a classificação social básica e universal da população em torno da ideia de raça. 
identificação de necessidades e deficiências que precisam ser superadas), que para o conhecimento destas sociedades a para o conhecimento dessas sociedades a partir das suas especificidades histórico-culturais. Existe uma extraordinária continuidades entre as diferentes formas nas quais os saberes eurocêntricos tem legitimado a missão civilizadora/normatizadora a partir das deficiências desvios ao padrão normal do civilizado - de outras sociedades ${ }^{11}$ (LANDER, 2000:11 - grifo nosso - tradução livre).

Os principais pressupostos fundantes dos saberes sociais modernos são:

[...] a cosmovisão que demonstra os pressupostos fundantes a toda construção dos saberes sociais modernos. Esta cosmovisão tem como eixo articulador central a ideia de modernidade, nação que é capturada completamente através de quatro dimensões básicas: 1) a visão universal da história associada a ideia de progresso (a partir do qual se constrói a classificação e hierarquização de todos os povos e continente, e experiências históricas); 2) a 'naturalização' tanto das relações sociais como da 'natureza humana' da sociedade liberal-capitalista; 3) a naturalização e ontologização das múltiplas separações próprias dessa sociedade; 4) a necessária superioridade dos saberes que produzem essa sociedade (a ciência) sobre todo outra forma de $\operatorname{saber}^{12}$ (LANDER, 2000:9 - tradução livre).

Neste sentido, o projeto de modernidade continua a interferir de diversas formas na produção de saberes que legitimam a missão colonial. Tal projeto foi formulado por filósofos do iluminismo e se baseava no desenvolvimento de uma ciência objetiva, uma moral universal e uma lei e uma arte autônomos que são regulados por lógicas próprias. E também, pela construção de separações, divisões e dicotomias ${ }^{13}$ (LANDER, 2000:6).

Desta maneira, o conjunto das separações está baseada na noção do caráter objetivo e universal do conhecimento científico e é articulado com a separação dos saberes sociais da ciência moderna com as demais culturas. Neste sentido, há o processo de cientificação da

11 "En este sentido es posible afirmar que, en todo el mundo ex-colonial, las ciencias sociales han servido más para el establecimiento de contrastes con la experiencia histórico cultural universal (normal) de la experiencia europea, (herramientas en este sentido de identificación de carencias y deficiencias que tienen que ser superadas), que para el conocimiento de esas sociedades a partir de sus especificidades histórico culturales. Existe una extraordinaria continuidad entre las diferentes formas en las cuales los saberes eurocéntricos han legitimado la misión civilizadora/normalizadora a partir de las deficiencias - desviaciones respecto al patrón normal de lo civilizado - de otras sociedades”(LANDER, 2000:11 - grifo nosso).

${ }_{12}^{2}[. .$.$] la cosmovisión que aporta los presupuestos fundantes a todo el edificio de los saberes sociales modernos.$ Esta cosmovisión tiene como eje articulador central la idea de modernidad, noción que captura complejamente cuatro dimensiones básicas: 1) la visión universal de la historia asociada a la idea del progreso (a partir de la cual se construye la clasificación y jerarquización de todos los pueblos y continentes, y experiencias históricas); 2) la 'naturalización' tanto de las relaciones sociales como de la 'naturaleza humana' de la sociedad liberal-capitalista; 3) la naturalización u ontologización de las múltiples separaciones propias de esa sociedad; 4) la necesaria superioridad de los saberes que produce esa sociedad ('ciencia') sobre todo otro saber (LANDER, 2000:9).

${ }^{13}$ Destacam-se as seguintes separações: a) de ordem religiosa (a principal diferença consiste na reflexão de que as crenças judeo-cristãs não contem inibições do controle da natureza pelos seres humanos) (LANDER, 2000:5); b) a separação entre corpo e a mente, que geram uma fissura ontológica de construção de um conhecimento descorporeizado e descontextualizado, que pretende ser objetivo e universal (sem-subjetividad) (LANDER, 2000:5); c) a população geral e um grupo seleto de especialistas, que gera o crescimento da distância entre a cultura dos especialistas e do público mais amplo (LANDER, 2000:6); d) a diferença absoluta entre natureza e cultura, entre ciência e sociedade (LANDER, 2000:11). 
sociedade liberal, com a seu padrão objetivo, universal, e consequentemente natural (LANDER, 2000:10).

Através da colonialidade, as disciplinas científicas no âmbito das ciências sociais são resultantes dos seguintes fatores: a) supõe-se a existência de um relato universal que leva todos os povos 'primitivos ou tradicionais' ao moderno, e a sociedade industrial liberal constitui a expressão mais avançada deste processo histórico e a sociedade liberal é uma norma universal que representa o único futuro possível de todas as culturas e povos; b) Diante o caráter universal da experiência histórica europeia, as formas de conhecimento desenvolvidas por esta sociedade se transformam em únicas formas válidas, objetivas e universais. E as categoriais e conceitos (como por exemplo, do Estado, da economia e da sociedade civil) se convertem enquanto perspectivas universais que definem o dever-ser de todos os povos do planeta (LANDER, 2000:10).

A colonialidade do saber reproduz e representa diversos problemas para a construção do conhecimento na atualidade; afinal, contribuem por ocultar, negar e subordinar todas as expressões culturais diversas do padrão eurocêntrico-liberal (LANDER, 2000:11); E mais:

Na América Latina, as ciências sociais, na medida que tem buscado a objetividade
universal, tem contribuído para a busca, assumida pelas elites latino-americanas ao
largo de toda a história deste continente, da superação dos traços tradicionais e pré-
modernos que estão dificultando o progresso, e a transformação das sociedades a
imagem e semelhança das sociedades liberais e industriais ${ }^{14}$ (LANDER, 2000:1 -
tradução livre).

Diante do compromisso assumido pelas ciências sociais com a elite, torna-se necessária a busca por alternativas que confrontem o mundo moderno, excludente e desigual, o que exige o esforço de desconstrução do caráter universal e natural da sociedade capitalista e liberal (LANDER, 2000:4). O que requer "o questionamento das pretensões de objetividade e neutralidade dos principais instrumentos de naturalização e legitimação desta ordem social: o conjunto de saberes que conhecemos globalmente como ciências sociais" (LANDER, 2000:4 - tradução nossa).

\footnotetext{
14 "En América Latina, las ciencias sociales, en la medida en que han apelado a esta objetividad universal, han contribuido a la búsqueda, asumida por las elites latino-americanas a lo largo de toda la historia de este continente, de la 'superación' de los rasgos tradicionales y pre-modernos que han obstaculizado el progreso, y la transformación de estas sociedades a imagen y semejanza de las sociedades liberales-industriales" (LANDER, 2000:11).
} 


\section{O pensamento social latinoamericano tem produzido formas alternativas de} conhecer, questionando o caráter colonial/eurocêntrico dos saberes sociais sobre o continente (LANDER, 2000:12). Lander (2000:12) citando Montero apresenta:

[...] a partir de muitas vozes na busca por formas alternativas de conhecer existentes na América Latina nas últimas décadas, é possível falar da existência de um 'modo de ver o mundo, de interpretá-lo e de atuar sobre ele' que constitui propriamente uma episteme com a qual 'América Latina está exercendo sua capacidade de ver e ter uma outra perspectiva, colocando fim ao nosso lugar'. As ideias centrais articuladoras deste paradigma são, para Montero, as seguintes:

Uma concepção de comunidade e de participação com o saber popular, como formas de construção e de produzir uma episteme da relação.

A ideia de libertação através da práxis, que supõe a mobilização da consciência, e um sentido crítico que leva a desnaturalização das formas canônicas de aprender e se construir no mundo.

A redefinição do rol de pesquisadores sociais, o reconhecimento do outro como si mesmo e, portanto, o sujeito-objeto da pesquisa como um ator social e construtor de conhecimento.

O caráter histórico, indeterminado, indefinido, não acabado e relativo do conhecimento. A multiplicidade de vozes, de modos de vida, a pluralidade epistêmica.

A perspectiva da dependência e logo, da resistência. A tensão entre minorias e maiorias e todos os modos alternativos de fazer e de conhecer.

A revisão de métodos, os aportes e as transformações provocadas por eles ${ }^{15}$ (LANDER, 2000:12 - tradução livre).

Percebe-se a necessidade de identificar o caráter colonial e eurocêntrico das ciências sociais, para romper com pressupostos de objetividade, neutralidade e universalidade. Desta maneira, é possível refletir sobre a influência do 'saber colonial' para a manutenção do estado liberal e do desenvolvimento do capitalismo.

E ao mesmo tempo, é possível construir alternativas à colonialidade do saber, com novas formas, técnicas e teorias para a produção do conhecimento. Diante da hegemonia da colonialidade do saber, existem espaços de resistência, como o Programa Nacional de Educação na Reforma Agrária (PRONERA) e a Educação Popular, que reivindicam novos

15 " [...] a partir de las muchas voces en busca de formas alternativas de conocer que se han venido dando en América Latina en las últimas décadas, es posible hablar de la existencia de un 'modo de ver el mundo, de interpretarlo y de actuar sobre él' que constituye propiamente un episteme con el cual 'América Latina está ejerciendo su capacidad de ver e hacer desde una perspectiva Otra, colocando al fin en el lugar de Nosotros'. Las ideas centrales articuladoras de este paradigma son, para Montero, las siguientes: Una concepción de comunidad y de participación así como del saber popular, como formas de constitución y a la vez como producto de un episteme de relación. La idea de liberación a través de la praxis, que supone la movilización de la conciencia, y un sentido crítico que lleva a la desnaturalización de las formas canónicas de aprehender-construir-se en el mundo. La redefinición del rol de investigador social, el reconocimiento del Otro como Sí Mismo y por lo tanto la del sujeto-objeto de la investigación como actor social y constructor de conocimiento. El carácter histórico, indeterminado, indefinido, no acabado y relativo del conocimiento. La multiplicidad de voces, de mundos de vida, la pluralidad epistémica. La perspectiva de la dependencia y luego, la de resistencia. La tensión entre minorías y mayorías y los modos alternativos de hacer-conocer. La revisión de métodos, los aportes y las transformaciones provocados por ellos" (LANDER, 2000:12). 
fazeres, sob novas formas de pensar e refletir a realidade brasileira, construindo um conhecimento contextualizado, voltado para os(as) oprimidos(as) sociais, inter e transdisciplinar, de esforço coletivo e resultado de uma práxis.

\section{Considerações Finais}

Diante das formulações do presente artigo, percebe-se que a colonialidade do saber representa a continuidade do padrão colonial, de destruição das gentes, através do fechamento cultural e hierarquização das formas de conhecer. As ciências sociais, e consequentemente, a formulação sobre a produção do conhecimento, reproduz a lógica colonial. Ou seja, através da naturalização, apresenta o saber eurocêntrico enquanto única forma de se atingir o conhecimento.

A concepção da construção de um conhecimento universal aliado à ideia de progresso, que retrata uma hierarquia entre os povos, afinal, as formas de organização social consideradas diferentes do padrão organizacional europeu, são consideradas inferiores e primitivas. O saber 'ciência' é considerado superior em relação aos outros saberes, ao ser considerado o único válido, através dos pressupostos da objetividade, da universalidade e da neutralidade. Neste sentido, percebe-se que o padrão hegemônico de produção do conhecimento nas ciências sociais tem o seu aporte na colonialidade do saber, ou seja, os saberes funcionam para legitimar a missão civilizatória e contribuir com a manutenção das elites no poder.

No entanto, é possível a construção de conhecimento alternativo e que se contrapõe ao modelo autoritário da colonialidade do saber. E o Pronera representa uma destas possibilidades alternativas através da reinvenção de saberes e fazeres no âmbito da produção do conhecimento. Afinal, quando sujeitos coletivos de direito questionam o modelo hegemônico e reivindicam um novo mecanismo pedagógico e de formação há a construção de novos direitos, pautados pela libertação dos povos do campo frente à opressão colonial do saber.

Desta maneira, o Pronera, enquanto resultado da práxis dos movimentos sociais camponeses e construído em diálogo com a educação popular, traz alternativas ao modelo posto, afinal: corresponde à uma experiência popular de criação e institucionalização de direitos; dá enfoque aos oprimidos sociais, através do fortalecimento da identidade camponesa 
frente ao modelo agrícola dominante, questionando a 'neutralidade' científica; há valorização do contexto dos educandos, rompendo com a separação 'corpo e alma'; traz uma pluralidade epistêmica através da formação interdisciplinar e de várias regiões do país; ressalta o caráter participativo e coletivo da produção do conhecimento, como por exemplo, com o incentivo da pesquisa-ação e a ecologia do saber, o que contribui para a construção de uma libertação de opressões cotidianas através da práxis.

Desta maneira, o Pronera se apresenta enquanto experiência fundamental para pensar a universidade popular, ou seja, aquela que encara o Brasil enquanto problema (RIBEIRO, 1995). Tal popularização se dá através do conhecimento feito a partir de nós e não dos outros (europeus), afinal, questiona-se o modelo universal, natural e a pretensão objetiva e neutra da produção do conhecimento. Neste sentido, ressalta-se o caráter de resistência dos sujeitos coletivos que pautam o Pronera frente à colonialidade do saber eurocêntrico, na busca de novas formas de pensar, agir e refletir sobre os problemas do povo camponês latinoamericano.

\section{Referências Bibliográficas}

ANTUNES, Ângela. Paulo Freire. In PÉRICÁS, Luiz Bernardo; SECCO, Lincon Ferreira.Intérpretes do Brasil: clássicos, rebeldes e renegados. 1. ed. São Paulo:Boitempo, 2014.

DUSSEL, Enrique. 1492: el encubrimiento del otro: hacia el origen del mito de la modernidad. La Paz: UMSA. Facultad de Humanidades y Ciencias de la Educación/Plural Editores: La Paz, 1994. Disponível em: http://bibliotecavirtual.clacso.org.ar/clacso/otros/20111218114130/1942.pdf Acesso 04 de maio de 2015.

DUSSEL, Enrique. 20 Teses de Política. Tradução de Rodrigo Rodrigues. São Paulo: Expressão Popular, 2007.

FREIRE, Paulo. Pedagogia da autonomia. Saberes necessários à prática educativa. $16^{\circ}$ Edição. São Paulo: Paz e Terra. 1996.

INSTITUTO DE PESQUISA ECONÔMICA APLICADA (IPEA). II PNERA, Relatório da II Pesquisa Nacional sobre a Educação na Reforma Agrária. Brasília, 2015.

LANDER, Edgardo. Ciencias Sociales: saberes coloniales y eurocêntrico. InLANDER, Edgardo. La colonialidad del saber: eurocentrismo y ciencias sociales. Perspectivas latino-americanas. Buenos Aires - Consejo Latinoamericano de Ciencias Sociales (CLACSO), 2000. pp. 122- 155.

MARÉS, Carlos Frederico. A usurpação das terras e das gentes. 2013. Disponível em: http://www.direitosocioambiental.com.br/aula-usurpacao-das-terras-e-das-gentes/ Acesso 30/10/2014. MINISTÉRIO DO DESENVOLVIMENTO AGRÁRIO (MDA). Manual de Operações do Programa Nacional de Educação na Reforma Agrária, 2014.

MINISTÉRIO DO DESENVOLVIMENTO AGRÁRIO (MDA). Manual de Operações do PRONERA, 2011.

RIBEIRO, Darcy. Universidade pra quê. 1995.

SÁ, Lais Mourão. A questão camponesa e os desafios do Programa Residência Agrária. In MOLINA, Mônica Molina et al (org.). Educação do Campo e formação profissional: a experiência do Programa Residência Agrária. Brasília:MDA, 2009. pp. 272-185. 
SANTOS, Boaventura de Sousa. A universidade no século XXI: para uma reforma democrática e emancipatória da universidade, 2005.

SOUSA, Ranielle Caroline de. 'O direito achado no campo': a construção da liberdade e da igualdade na experiência da Turma Evandro Lins e Silva. Dissertação. Faculdade de Direito. Universidade de Brasília (UnB):Brasília, 2012.

SOUSA, Ranielle Caroline de; FREITAS, Cleuton César Ripol de. Educação jurídica e ações afirmativas: formação e perfil da turma especial em Direito.In Anais do Congresso Latinoamericano de Direitos Humanos e Pluralismo Jurídico. Florianópolis:Editora Dom Quixote, 2008.

SOUSA JÚNIOR, José Geraldo de. Direito como Liberdade: O Direito Achado na Rua. Experiências Populares de Criação do Direito. Tese. Faculdade de Direito. Universidade de Brasília (UnB): Brasília, 2008.

QUIJANO, Aníbal. Colonialidad del poder, eurocentrismo y América Latina. In LANDER, Edgardo. La colonialidad del saber: eurocentrismo y ciencias sociales. Perspectivas latino-americanas. Buenos Aires - Consejo Latinoamericano de Ciencias Sociales (CLACSO), 2000. pp. 122- 155.

UNIVERSidAde federal DE GOIÁS (UFG). Projeto Político Pedagógico do Curso de Especialização em Direitos Sociais do Campo. 2012. 